\title{
The Exploration of the Enterprise Cultivation Scheme of the Energy and Power Engineering Major
}

\author{
Dong Liu, Qian Wang, Can Kang, Weixing Xu \\ School of Energy and Power Engineering \\ Jiangsu University \\ Zhenjiang, China
}

\begin{abstract}
This paper aims at exploring the reform that caused by practice ineffectiveness, low participation and insufficient enthusiasm of Energy and Power Engineering professional undergraduates. Based on the goal of cultivating talents with Emerging Engineering Education, this paper optimizes the design of practical training program for Energy and Power Engineering talents, and combines practice goal and practice task with the actual situation of enterprises. It also improves the evaluation method, gains the students ' enthusiasm based on practice and encourages students to think hard and innovate bravely, which serve as the main basis for the evaluation of practical links. The measures above have effectively improved the quality of outside school practice, and strengthened students' ability and quality. The reform has achieved the expected goal.
\end{abstract}

Keywords-Enterprise cultivation scheme; Ability and quality; Reform of assessment mode; Excellence engineer education program

\section{INTRODUCTION}

On February 18th, 2017, the Symposium on the Development Strategy of Engineering Education in comprehensive universities was held in Fudan University. It was put forward that colleges and universities in China should quicken the construction and development of Emerging Engineering Education. The construction and development of new engineering are in the setting of the new economy and industry. The New Structure of disciplines and professions that combined new engineering with traditional engineering should be set up. The New Mode of training talents in Engineering Education should be explored. The New System of engineering education with Chinese characteristics should be established and perfected. The Emerging Engineering Education construction on the one hand to set up and develop a number of emerging engineering major, on the other hand to promote the existing engineering major reform and innovation.

The Energy and Power Engineering Major in Jiangsu University was selected by Education Department in the first batch as "Excellence Engineer Education Program ", which highlights the cultivation of students ' engineering quality. It is necessary for students to be provided a good engineering environment, so that students can obtain a more comprehensive engineering quality [1-3]. Therefore, practical teaching is of great significance. The two important links in practical teaching are the practice in school and the practice out of school. The former one makes students possess basic engineering ability through experiment and scientific research training, and the latter one is as the improvement and supplement of the practice in school. It makes students improve their comprehension of professional knowledge in practice, mastering information on more advanced manufacturing and production process, being familiar with the design, experiment and optimization of related products, cultivating students innovative ability and engineering ability [4].

At present, the major has established 4 National Engineering Practice Education Center and 65 Excellent Talent Enterprise Practice Base. Each year, Junior and senior undergraduates in distinguished classes are selected to the enterprise to practice. After years of construction, the internship base owns a group of experienced enterprise mentors. They participate in students curriculum design and graduation design guidance, and also participate in the student's graduation design reply. From the perspective of cultivation effect, the effect of students ' practice is quite different. Some excellent students can, under the guidance of the engineer, not only complete the design of the whole pump, but also make a comprehensive analysis of its structure reliability, pump internal flow field and pump performance, putting forward suggestions for improvement. And some suggestions are adopted by enterprises and successfully applied to solve the practical engineering problems. Some other students can only complete the most basic graduation design tasks, whose qualities have little difference with the work of students in school. We think that this part of the students did not reach the target of the internship in the enterprise. The main reason is that these parts of the students are of low participation in the practice process, and enthusiasm is not enough. They are easily tired of the simple and repetitive daily work. When facing problems in practice, they cannot actively think and solve, resulting in inefficient practice. 


\section{REFORM METHODS}

In order to achieve the goal of cultivating innovative talents in Emerging Engineering Education, we have reformed the outside school practical links, including:

\section{A. Establishing an Enterprise cultivation scheme Aimed at Cultivating Students' Ability.}

Practice Teaching is the key link to complete the knowledge transfer and skill training of engineering majors in colleges and universities, and also the key to realize the goal of talent cultivation. The requirements of the Emerging Engineering Education to personnel training should be defined, to formulate the training goals related to the practice link, and then to "how to train the talented person ", then formulate the practice teaching training plan. The training Plan of enterprise practice links are divided into 3 phases to implement, respectively, in the sixth, seventh and eighth semesters.

In the sixth semester, a 4-week internship is organized in a centralized manner, including energy and power engineering professional production and technology internship. Students are required to understand the current situation and development trends of productions, and have the ability to collect and summarize relevant technical information at home and abroad. They are also required to understand the working principle of the product and be familiar with the product structure, having the ability to analyze the components function They should also be familiar with the material type and performance of product manufacture, know well the working characteristic of the machining equipment, master the blade forming technology, master the production process and process document design, have the ability to operate the CNC machining system, and be familiar with the product precision testing technology and method.

In the seventh semester, a 12-week internship is conducted in a decentralized manner. Through the interview selection, students are scattered to various excellence practice base. The practice includes: fluid mechanical performance testing and data processing capacity learning, cutting-edge technology of fluid machinery products research, curriculum design and integrated design I (Graduation Design). Students are required to master the experimental methods of product performance and the conditions of use of test equipment; to be familiar with product performance and economic evaluation criteria and indicators; to have the ability of experimental data processing and analysis; to have the ability to prepare product experiment Plan and compose experiment report; to cultivate good scientific research spirit and correct scientific research method; to have strong innovation ability; to write research report; to have initial ability to access data; to master initial computational design ability; to have ability to write reports; to gain communication, presentation and collaboration skills; to master drawing skills; to master knowledge and skills in product design; to have strong computer CAD drawing ability; to gain good communication and communication skills; to have a certain sense of innovation and innovative design capabilities.

The Practice links in Eighth semester continue the way in the Seventh semester. There is a 16 -weeek practice, including: graduation design, fluid machinery synthesis Design (II)Special fluid mechanical product design training. Students are required to master the basic knowledge and skills of product design; to have the ability to use CFD software to calculate and analyze flow field; to master good communication and communication skills; to have the ability of innovation and design; to use CFD software for the flow field analysis of special fluid machinery products, optimize flow field design, and improve the efficiency; to use ANASYS finite element analysis software for special fluid mechanical products structural strength calculation, and optimize the design; to acquire the ability of initial project implementation and management; to have a good sense of cooperation and team spirit.

\section{B. Improving Students' Participation and Enthusiasm in Enterprise Internship}

In view of the lack of attention and enthusiasm of students to practice, making students realize the importance of practice is an important way to improve professional practical skills and a good platform to improve comprehensive quality, through strengthening the mobilization of interns, motivating and guiding students to pay attention to the internship. Practice, in accordance with the actual enterprise, adopts rotating induction, competition induction, interest induction, in order to enhance student internship interest and motivation. The initiative of student participation and the innovation of problem-solving are included in the evaluation index of Practice examination, which encourages students to explore and find problems motivatively in the practical process, and to consider and propose solutions. In addition, the arranged communication links during the practice are conducive to display the student's personal comprehensive quality. As a result, the internship enterprises understand students further, and the business retention space of students can be improved.

\section{Paying Attention to the Cultivation of Both Students' Ability and Quality}

Enterprise practice is developed mainly through the "Three Chain" main line, namely Production Chain, Technology Chain and Management Chain. As figure.1 shows, the link of Production Chain is based on professional cognition, introducing advanced technology and manufacture, so that undergraduates can be familiar with the manufacturing process of pump products. Technology Chain is on the basis of pump hydraulic design, structural design, making students understand the design of product performance by performance testing and internal flow testing means. It also improves the efficiency of the pump by optimizing the application of the technology. In the course of the implementation of Management Chain, students are arranged into project teams of the enterprise. It further enhances the student's engineering ability through project research, project budget, implementation management and so on. In the aspect of quality training, the students ' engineering quality, scientific quality and humanistic quality can be cultivated through pioneering lectures, alumni interviews, engineer reports and corporate culture. 


\section{The Main Line of Practice of "Three Chains" in Enterprises}

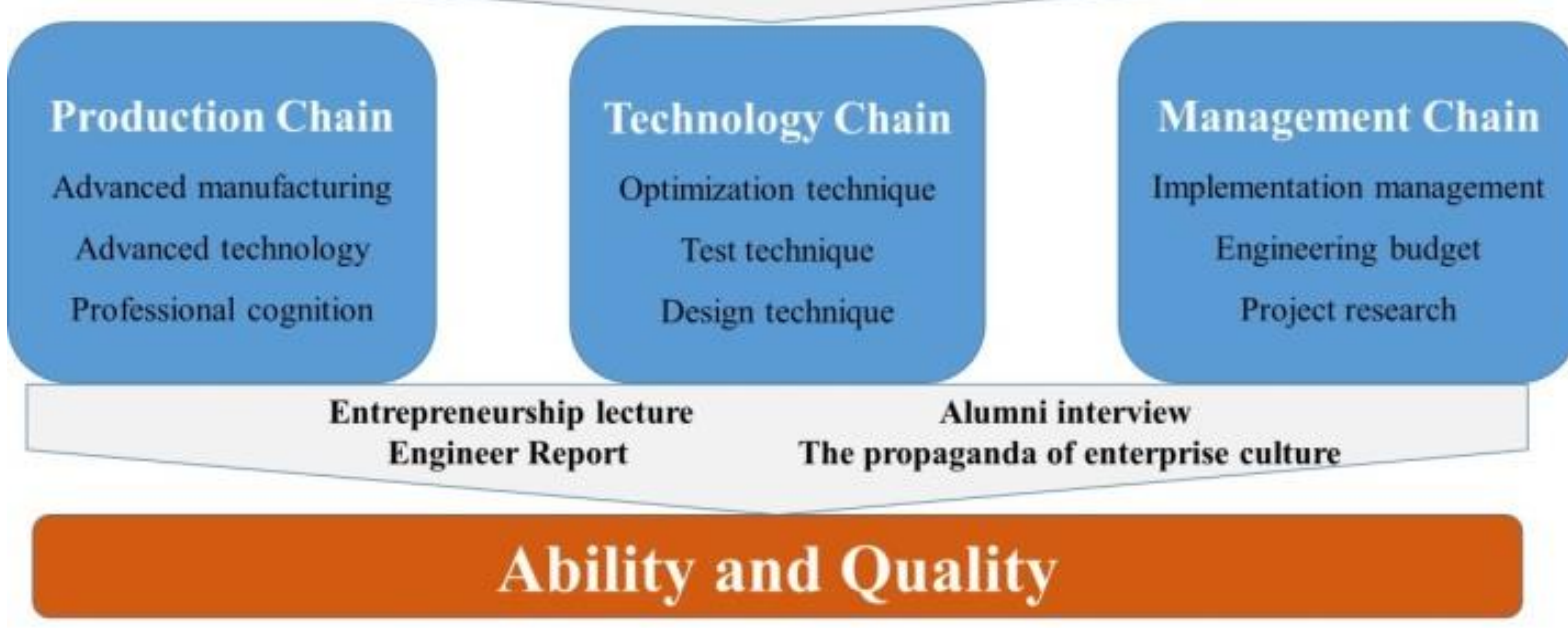

Fig. 1. A practical teaching system that based on both ability and quality

\section{Assessment Mode Reform}

Enterprise practice assessment is an important to check the effect of students' practice and guarantee the quality of practice teaching. Reforming the practice examination way and giving full play to check the positive function help to improve the effect of outside school practice. Traditional practice methods: attendance accounted for $20 \%$, calculation reports and drawings accounted for $80 \%$. The goal of this method is narrow and the way is single, ignoring the main role of students and enterprises in practice. The reformed assessment is divided into: attendance accounted for $20 \%$, calculation reports and drawings accounted for $40 \%$, Enterprise scoring accounted for $20 \%$, and curriculum defense accounted for $20 \%$. The Enterprise Engineer is invited to the reply process, and the enterprise grading is mainly from the students initiative to practice and innovation to solve problems and so on. Through these reforms, we can comprehensively evaluate the effect of practical links and improve students ' initiative in practice.

\section{CONCLUSION}

After the design of energy and power engineering professionals training outside school practice program has been optimized, a diversified practice teaching module has been constructed. Many methods, like promoting students ' participation in practice, paying attention to the cultivation of students' ability and quality, reforming the methods of examination and so on, has effectively improved the outside school practical effect of undergraduates who majored in Energy and Power Engineering.

\section{ACKNOWLEDGEMENT}

This study is supported by the Teaching Reform Project of Jiangsu University (2017JGZD020), the Teaching Reform Project of Energy and Power Engineering Teaching in Colleges and Universities Steering Committee (NDXGK2017Y-02), and Top-notch Academic Programs Project of Jiangsu Higher Education Institutions (PPZY2015A029).

\section{REFERENCES}

[1] C.J. Liu, W.M. Gan, W.D. Jin, "Enterprise cultivation scheme and practice of the "Plan for Educating and Training Outstanding Engineers" in application-oriented universities," China modern educational equipment, 2014, pp. 113-116.

[2] C.J. Wang, Y.Z. Shen, R.H.Huang, "Training Mode on the Excellent Mechanical Engineers through School-Enterprise Cooperation," China geological education, 2014, pp. 14-17.

[3] T.X. Jin, G.L. Li, "Discussion on the Practical Teaching System for Energy and Power Engineering Major Based on the Plan for Educating and Training Outstanding Engineers," China Modern Educational Equipment, 2016, pp. 96-99.

[4] X.L. Ju, B. Lin, Q.H. Yu, "Exploration of Reform on Energy and Power Engineering Training Program under the Background of "The Plan of Excellent Engineering"," Education Teaching Forum, 2016, pp. 124-125. 